\title{
Special Issue - Papers from International Session, JAST Tribology Conference, Fukui, September 2010
}

The Japanese Society of Tribologists organized the international session as one of the sessions held in JAST Tribology Conference, Fukui, September 2010. One part of the boundary lubrication session organized by Professor Shigeyuki Mori from Iwate University and Professor Masabumi Masuko from Tokyo Institute of Technology also joined with the international session.

After the opening remarks, Professor Nicholas D. Spencer from Swiss Federal Institute of Technology gave an invited lecture. Fourteen general presentations followed by two invited speeches by Professor Teruo Murakami from Kyushu University and Dr. Rowena Crockett from Swiss Federal Institute for Materials Research and Technology were contributed in this session. In order to distribute their high-quality research work, JAST invited fourteen presenters who made the general speech to submit their contributions to Tribology Online as peer reviewed papers. the papers submitted subsequently underwent the normal peer review process by multiple reviewers. Among the papers submitted, four papers were selected for publication in this special issue.

The organizing committee wishes to express their sincere appreciation to all the authors and participants at the international session. The guest editor also would like to express his acknowledgement to all the reviewers.

\section{Guest Editor}

Tomoaki Iwai 